\title{
Soluble CD163 for Prediction of High-Risk Esophageal Varices and Variceal Hemorrhage in Patients with Liver Cirrhosis
}

\author{
Mohamed Yousri Taher ${ }^{\mathrm{a}} \quad$ Abeer El-Hadidi $^{\mathrm{b}}$ Assem El-Shendidi ${ }^{\mathrm{a}}$ \\ Ahmed Sedky ${ }^{\mathrm{a}}$ \\ ${ }^{a}$ Department of Internal Medicine (Hepatology Division), Faculty of Medicine, Alexandria University, \\ Alexandria, Egypt; ${ }^{b}$ Department of Clinical and Chemical Pathology, Faculty of Medicine, Alexandria University, \\ Alexandria, Egypt
}

\section{Keywords}

Soluble CD163 · Portal hypertension · Esophageal varices · Variceal hemorrhage

\section{Abstract}

Introduction: Activation of hepatic macrophages in liver disease is pathogenically related to portal hypertension $(\mathrm{PH})$. Soluble CD163 (sCD163) is shed in blood by activated macrophages and may predict $\mathrm{PH}$ progression noninvasively. This study was designed to investigate the relation of serum sCD163 to the grade and bleeding risk of esophageal varices (EV) and its role for prediction of variceal hemorrhage (VH). Methods: The study included cirrhotic patients divided into 3 groups: patients who presented with acute upper gastrointestinal bleeding (UGIB) proved to originate from EV on endoscopy, patients without any history of UGIB but who revealed EV on surveillance endoscopy, and patients without endoscopic evidence of varices. Variceal grade and risk signs and bleeding stigmata were noted simultaneously with measurement of serum sCD163 concentration. Results: Serum sCD163 concentration showed a significant increase in cirrhotic patients compared to healthy subjects $(p<0.001)$ with a stepwise increase among the group without varices, nonbleeder group, and bleeder group sequentially. Serum sCD163 levels corre- lated positively with the variceal grade and risk signs in both the bleeder and nonbleeder groups $(p=0.002, p<0.001$ and $p=0.004, p<0.001$, respectively). Serum sCD163 at a cutoff value of $3.6 \mathrm{mg} / \mathrm{L}$ performed significantly for prediction of EV presence (AUC $=0.888$ ). Serum $S C D 163$ at a cutoff value $>4 \mathrm{mg} / \mathrm{L}$ significantly predicted large-size and high-risk EV (AUC $=0.910$ and $A \cup C=0.939$, respectively) and the index bleed risk (AUC $=0.977$ ). Serum $\mathrm{SCD} 163$ at a cutoff value $>4.05$ $\mathrm{mg} / \mathrm{L}$ modestly discriminated bleeding EV from those that had never bled (AUC $=0.811$ ). Conclusions: Serum SCD163 levels accurately predicted high-grade and high-risk EV and could help plan for primary prophylaxis. However, it modestly identified $\mathrm{VH}$ occurrence, and endoscopy would be required to make a definitive diagnosis.

\footnotetext{
(C) 2021 Sociedade Portuguesa de Gastrenterologia Published by S. Karger AG, Basel
}

\section{CD163 solúvel para a predição de varizes esofágicas de alto risco e hemorragia digestiva varicosa em doentes com cirrose hepática}

Palavras Chave

CD163 solúvel · Hipertensão portal · Varizes esofágicas · Hemorragia varicosa karger@karger.com www.karger.com/pjg

Karger $\stackrel{\text { ' }}{5}$

BOPEN ACCESS (c) 2021 Sociedade Portuguesa de Gastrenterologia Published by S. Karger AG, Basel

This is an Open Access article licensed under the Creative Commons Attribution-NonCommercial-4.0 International License (CC BY-NC) (http://www.karger.com/Services/OpenAccessLicense), applicable to the online version of the article only. Usage and distribution for commercial purposes requires written permission.
Correspondence to:

Assem El-Shendidi, assem.shendidi@alexmed.edu.eg 


\section{Resumo}

Introdução: A ativação dos macrófagos hepáticos na doença hepática está patogenicamente relacionada com a hipertensão portal (HP). O CD163 solúvel (sCD163) é libertado no sangue por macrófagos ativados e pode predizer a progressão da HP de forma não invasiva. Este estudo foi desenhado para investigar a relação do sCD163 ao grau e risco hemorrágico por varizes esofágicas (VE) e o seu papel da predição na hemorragia varicosa (HV). Métodos: Estudo incluiu doentes cirróticos divididos em três grupos: doentes com hemorragia digestiva alta aguda (HDA) por VE, doentes sem história de HDA mas com VE comprovadas endoscopicamente e doentes sem evidência de VE. O grau, sinais de risco e estigmas hemorrágicos das varizes foram avaliados simultaneamente com a medição sérica da concentração de sCD163. Resultados: A concentração sérica de sCD163 apresentou um aumento significativo nos doentes cirróticos comparados com os indivíduos saudáveis ( $>4 \mathrm{mg} / \mathrm{L}$ ) previu de forma significativa VE grandes e de alto-risco ( $A U C=0.910$ e $A U C=0.939$ respectivamente) e o risco index-hemorrágico ( $A U C=$ 0.977). O valor cut-off de SCD163 sérico $>4.05 \mathrm{mg} / \mathrm{L}$ discriminou de forma modesta VE sangrantes daquelas que nunca sangraram ( $A \cup C=0.811$ ). Conclusões: Os níveis de sCD163 sérico predizem com acuidade VE grandes e de alto-risco e podem ajudar a planear a profilaxia primária. Contudo, apenas modestamente identificaram a ocorrência de HV, sendo a endoscopia necessária para fazer um diagnóstico definitivo.

(C) 2021 Sociedade Portuguesa de Gastrenterologia Publicado por S. Karger AG, Basel

\section{Introduction}

Development of portal hypertension $(\mathrm{PH})$ is a main cornerstone in the natural history of any chronic liver disease (CLD) regardless of the etiological cause and is responsible for the majority of complications [1]. Pathological increase in the portal venous pressure determined as the hepatic venous pressure gradient (HVPG) above the threshold of $10 \mathrm{~mm} \mathrm{Hg}$ defines clinically significant $\mathrm{PH}$ and is associated with an increased risk of developing gastroesophageal varices (GEV) and overt clinical decompensation [2]. GEV develop at a rate of $7-8 \%$ per year in patients with compensated cirrhosis, and progression from small to large varices occurs at a rate of $10-12 \%$ per year, with decompensated cirrhosis being an independent predictor of progression [3]. Variceal hemorrhage $(\mathrm{VH})$ occurs at a rate of around $10-15 \%$ per year and de-

Soluble CD163 and Esophageal Variceal Hemorrhage pends on the severity of liver disease, the size of varices and presence of red wale marks on endoscopy $[3,4]$. Sixweek mortality, which is recognized as the primary end point to assess the impact of therapies for acute $\mathrm{VH}$, ranges between 15 and $25 \%$ [4]. If untreated, recurrent $\mathrm{VH}$ occurs in $60 \%$ of patients, usually within $1-2$ years of the index bleed $[3,5]$. In patients with GEV, an HVPG $>12$ $\mathrm{mm} \mathrm{Hg}$ identifies bleeding risk, an HVPG $>16 \mathrm{~mm} \mathrm{Hg}$ indicates a higher risk of death, and an HVPG $\geq 20 \mathrm{~mm}$ $\mathrm{Hg}$ predicts failure to control bleeding, early rebleeding, and death during acute $\mathrm{VH}[5,6]$. Despite its excellent diagnostic and prognostic value, HVPG measurements require specific expertise, are invasive, relatively expensive, and available only in specialized centers.

There is consensus to perform esophagogastroduodenoscopy when the diagnosis of cirrhosis is established to screen for GEV and determine the care of varices [3]. Because endoscopy is a costly invasive procedure and may engender a large number of negative examinations, several authors have attempted to develop noninvasive reliable methods that could predict portal pressure so as to triage some patients [7]. The Baveno VI criteria were verified in several clinical studies to stratify high-risk esophageal varices (EV), and their use can obviate up to $20 \%$ of unnecessary endoscopies and merely $3-4 \%$ of patients with EV who need treatment would be missed $[4,8,9]$. The discriminative accuracy of noninvasive methods in predicting the presence of any GEV may be limited, although fairly accurate to rule out high-risk varices in patients with advanced CLD [10].

CD163 is a $130-\mathrm{kDa}$ macrophage lineage-specific protein that acts as the scavenger receptor of the tight complex of hemoglobin-haptoglobin formed instantly in plasma when hemoglobin escapes red blood cells during intravascular hemolysis [11]. A soluble form of CD163 (sCD163) is present in the plasma and other body fluids, at least partly due to proteolytic shedding of the receptor from monocytes and macrophages [12]. The protein is constitutively released from the cells; however, in case of macrophage recruitment, the concentration increases acutely due to metalloproteinase-mediated cleavage near the cell membrane, and therefore sCD163 works as a specific biomarker of macrophage activation in various inflammatory diseases, such as hemophagocytic syndrome, sepsis, and liver diseases $[12,13]$. Concentration of sCD163 was noticed to increase by $12 \%$ from the portal to the hepatic vein, which confirmed the hypothesis that sCD163 is mainly produced by the resident hepatic macrophages and can be viewed as a reflection of Kupffer cell activation in liver diseases [14]. Overexpression of CD163 
in the blood and the liver has been demonstrated in viral and alcoholic hepatitis and acute liver failure [14-16]. In liver cirrhosis, sCD163 associates with liver disease severity scores, increases steeply with HVPG elevations, and accurately predicts disease progression $[14,17]$. The rationale for using inflammatory serum biomarkers is based on the fact that $\mathrm{PH}$ is pathogenically related to liver injury and fibrosis, and that in turn these are associated with the activation of inflammatory pathways [18].

Therefore, the present work was designed to investigate the relation of serum sCD163, and other calculated noninvasive parameters, to the grade and bleeding risk of $\mathrm{EV}$ and the role for prediction of $\mathrm{VH}$ in patients with liver cirrhosis.

\section{Materials and Methods}

The present study included 100 patients with hepatitis $C$ virus (HCV)-related liver cirrhosis who were referred to the Hepatobiliary Unit at Alexandria Main University Hospital. The diagnosis of liver cirrhosis was based on clinical, laboratory, and ultrasonographic findings. Also, 20 age- and sex-matched healthy subjects with no evidence of liver disease were included as control group.

Patients included in the study were divided into 3 groups. Group I (bleeder group) included 40 cirrhotic patients who presented with acute upper gastrointestinal bleeding (UGIB) proved to originate from EV on endoscopy. Group II (nonbleeder group) included 40 cirrhotic patients without any history of UGIB but revealed EV on surveillance endoscopy. Group III (no-varices group) included 20 cirrhotic patients without any history of UGIB and did not reveal any EV on surveillance endoscopy. Patients with $\mathrm{PH}$ were excluded from the study in cases of noncirrhotic $\mathrm{PH}$, portal vein thrombosis or cavernomatosis, current use of noncardio-selective $\beta$-blockers, previous endoscopic variceal ligation or sclerotherapy, transjugular intrahepatic portosystemic stent placement, previous portosystemic shunt surgery, splenectomy or hepatectomy, serious infections or inflammatory diseases, any kind of malignancy like hepatic or esophageal cancer, or chronic diseases such as diabetes mellitus and cardiopulmonary or renal diseases.

All patients included in the study were evaluated clinically as regards age, sex, detailed history of UGIB, and manifestations of CLD. Routine laboratory investigations done for all patients and healthy subjects involved complete blood picture and liver test profile. Abdominal ultrasonography was done to assess echo texture of the liver and the presence of cirrhosis, the presence of ascites, and the splenic size that is taken as the maximal bipolar diameter from the inferior splenic tip to the superiomedial extremity. Severity of liver disease in patients with liver cirrhosis was identified according to the Child-Pugh class and score. Esophagogastroduodenoscopy was done for all patients to assess the presence of EV, their size and grade, the risk signs, and the stigmata of recent bleeding. EV were simply graded into small or large by quantitative size assessment with a suggested cutoff diameter of $5 \mathrm{~mm}$, whereby large varices were those $>5 \mathrm{~mm}$ in size [2]. The diagnosis of variceal risk signs is made when diagnostic endoscopy showed any of the following: red wale marks (defined as longitudinal dilated venules resembling whip marks on the variceal surface), or red spots (defined as localized reddish mucosal area or spots on the mucosal surface of a varix) $[2,3]$. The diagnosis of $\mathrm{VH}$ is made when diagnostic endoscopy showed any of the following: active bleeding from a varix, a "white nipple" overlying a varix, clots overlying a varix, or varices with no other potential source of bleeding [2,3]. Management of GEV and $\mathrm{VH}$ was made according to the clinical guidelines $[3,4]$.

\section{Calculation of Noninvasive Parameters}

- Aspartate aminotransferase-to-platelet ratio index (APRI) calculated using Wai's formula as (aspartate aminotransferase [IU/L]/upper limit of normal [IU/L]) $\times 100 /$ platelet count $\left(10^{9}\right.$ cell number/L) [19]

- Fibrosis-4 score (FIB-4) calculated using Sterling's formula as (age [years] $\times$ aspartate aminotransferase [IU/L])/(platelet count $\left[10^{9}\right.$ cell number/L] $\times \sqrt{ }$ alanine aminotransferase [IU/L]) [20]

- Platelet count-to-spleen diameter ratio (PSR) calculated as platelet count $\left(10^{9}\right.$ cell number/L)/spleen diameter (millimeters) [21].

\section{Measurement of Serum sCD163 Level}

Quantitative determination of serum sCD163 levels in all patients and healthy subjects included in the study was performed using a commercially available enzyme-linked immunosorbent assay (ELISA) kit (Cat. No.: E-02073hu, Cloud-Clone Corp., Houston, TX, USA) according to the manufacturer instructions [22]. The serum sCD163 concentration was expressed as milligrams per liter.

\section{Statistical Analysis}

Data were fed to the computer and analyzed using the Statistical Package for Social Sciences (SPSS) software version 20.0. (Armonk, NY, USA; IBM Corp.). Quantitative data were described as range, mean $\pm \mathrm{SD}$, and median. Qualitative data were described as number and percentage. The Kolmogorov-Smirnov test was used to verify the normality of data distribution. Statistical significance of the obtained results was judged at the $p<0.05$ level. All calculated $p$ values were 2 -tailed. The $\chi^{2}$ test and Fisher's exact test with Monte Carlo correction were used for comparison between different groups with respect to categorical variables, as appropriate. Comparisons between 2 groups for normally distributed numeri$\mathrm{cal}$ variables were done using the Student $t$ test. The Mann-Whitney $\mathrm{U}$ test was used to compare between 2 groups for nonnormally distributed numerical variables. Comparisons between more than 2 groups as regards normally distributed numerical variables will be performed by the one-way analysis of variance test with post hoc (Tukey's) analysis. Comparisons between more than 2 groups as regards nonnormally distributed numerical variables will be performed by the Kruskal-Wallis test with post hoc (Dunn's) analysis. Pearson's correlation coefficient was used to measure the strength of association of the normally distributed numerical variables. Spearman's correlation coefficient was used to measure the strength of association of the nonnormally distributed numerical variables. The receiver-operating characteristic curve was plotted to determine the cutoff value, sensitivity, specificity, and area under the receiver-operating characteristic curve (AUC) for serum sCD163 concentration and the other calculated noninvasive parameters to discriminate between the different patient groups. The positive predictive value (PPV) and negative predictive value (NPV) were calculated for the cutoff value which showed the highest sensitivity and specificity. 
Table 1. Baseline clinical and biochemical data, calculated noninvasive parameters, and endoscopic findings of the groups of cirrhotic patients included in the study

\begin{tabular}{|c|c|c|c|c|}
\hline & $\begin{array}{l}\text { Bleeder group } \\
(n=40)\end{array}$ & $\begin{array}{l}\text { Nonbleeder group } \\
(n=40)\end{array}$ & $\begin{array}{l}\text { No-varices group } \\
(n=20)\end{array}$ & $p$ value \\
\hline \multicolumn{5}{|l|}{ Age, years } \\
\hline Range & $41-65$ & $40-65$ & $35-73$ & \\
\hline Mean \pm SD & $55.88 \pm 7.133$ & $56.78 \pm 6.796$ & $52 \pm 7.89$ & 0.066 \\
\hline \multicolumn{5}{|l|}{ Sex } \\
\hline Male:female & $29: 11$ & $18: 22$ & $11: 9$ & $0.022^{*}$ \\
\hline \multicolumn{5}{|l|}{ Hemoglobin level, g/dL } \\
\hline Mean \pm SD & $9.00 \pm 0.953$ & $11.06 \pm 1.097$ & $12.06 \pm 1.91$ & $<0.001^{*}$ \\
\hline \multicolumn{5}{|c|}{ Leukocyte count, $\times 10^{3} / \mathrm{mm}^{3}$} \\
\hline Mean \pm SD & $4.80 \pm 1.845$ & $5.74 \pm 1.801$ & $5.14 \pm 1.68$ & 0.069 \\
\hline \multicolumn{5}{|c|}{ Platelet count, $\times 10^{3} / \mathrm{mm}^{3}$} \\
\hline Mean \pm SD & $104.80 \pm 29.715$ & $127.23 \pm 24.288$ & $135.10 \pm 53.74$ & $0.002^{*}$ \\
\hline \multicolumn{5}{|l|}{ Serum AST, U/L } \\
\hline Mean \pm SD & $52.77 \pm 19.243$ & $50.78 \pm 19.112$ & $47.70 \pm 23.04$ & 0.660 \\
\hline \multicolumn{5}{|l|}{ Serum ALT, U/L } \\
\hline Mean \pm SD & $34.70 \pm 14.972$ & $35.63 \pm 15.256$ & $55.95 \pm 21.48$ & $<0.001^{*}$ \\
\hline \multicolumn{5}{|l|}{ Serum albumin, g/dL } \\
\hline Mean \pm SD & $3.13 \pm 0.433$ & $3.40 \pm 0.356$ & $3.40 \pm 0.52$ & $0.022^{*}$ \\
\hline \multicolumn{5}{|l|}{ Serum bilirubin, $\mathrm{mg} / \mathrm{dL}$} \\
\hline Mean \pm SD & $1.62 \pm 0.641$ & $1.15 \pm 0.549$ & $1.13 \pm 0.80$ & $0.002 *$ \\
\hline \multicolumn{5}{|c|}{ Prothrombin activity, $\%$} \\
\hline Mean \pm SD & $71.10 \pm 8.038$ & $75.12 \pm 11.411$ & $79.13 \pm 15.69$ & 0.034 \\
\hline \multicolumn{5}{|l|}{ Child-Pugh class } \\
\hline $\mathrm{A}: \mathrm{B}: \mathrm{C}$ & $24: 12: 4$ & $21: 16: 3$ & $15: 3: 2$ & 0.633 \\
\hline \multicolumn{5}{|l|}{ Child-Pugh score } \\
\hline Mean \pm SD & $6.82 \pm 1.318$ & $6.00 \pm 1.539$ & $5.70 \pm 2.0$ & $0.028^{*}$ \\
\hline \multicolumn{5}{|l|}{ Variceal grade } \\
\hline Small:large & $9: 31$ & $28: 12$ & NA & $<0.001^{*}$ \\
\hline \multicolumn{5}{|l|}{ Variceal risk signs } \\
\hline Absent:present & $8: 32$ & $26: 14$ & NA & $<0.001^{*}$ \\
\hline \multicolumn{5}{|c|}{ Congestive gastropathy } \\
\hline None:mild:severe & $0: 8: 32$ & $8: 18: 14$ & $9: 10: 1$ & $<0.001^{*}$ \\
\hline \multicolumn{5}{|l|}{ APRI } \\
\hline Mean \pm SD & $1.34 \pm 0.645$ & $1.02 \pm 0.460$ & $1.11 \pm 0.72$ & 0.055 \\
\hline \multicolumn{5}{|l|}{ FIB- 4} \\
\hline Mean \pm SD & $5.22 \pm 2.263$ & $3.91 \pm 1.150$ & $2.77 \pm 1.31$ & $<0.001^{*}$ \\
\hline \multicolumn{5}{|l|}{ PSR } \\
\hline Mean \pm SD & $606.89 \pm 231.346$ & $858.57 \pm 251.300$ & $997.65 \pm 436.48$ & $<0.001^{*}$ \\
\hline
\end{tabular}

ALT, alanine aminotransferase; AST, aspartate aminotransferase; APRI, aspartate aminotransferase-to-platelet count ratio index; FIB-4, fibrosis-4 index; PSR, platelet count-to-spleen diameter ratio; NA, not applicable. * Statistically significant at $p \leq 0.05$.

\section{Results}

Baseline clinical and biochemical data, calculated noninvasive parameters, and endoscopic findings of the groups of cirrhotic patients included in the study are presented concisely in Table 1.

Soluble CD163 and Esophageal Variceal Hemorrhage

\section{Serum sCD163 Level}

Serum sCD163 concentration ranged between 2.99 and 13.59 and 1.7 and $5.15 \mathrm{mg} / \mathrm{L}$ in cirrhotic patients of the bleeder group and the nonbleeder group, respectively, and it ranged between 1.56 and $3.6 \mathrm{mg} / \mathrm{L}$ in cirrhotic patients of the no-varices group, while it ranged between 1.5 and $2.7 \mathrm{mg} / \mathrm{L}$ in healthy subjects. The mean value of se- 
Table 2. Statistical comparison between the groups of cirrhotic patients included in the study and healthy subjects as regards soluble CD163 (sCD163) serum levels (mg/L)

\begin{tabular}{|c|c|c|c|c|}
\hline Parameter & $\begin{array}{l}\text { Bleeder group } \\
(n=40)\end{array}$ & $\begin{array}{l}\text { Nonbleeder group } \\
(n=40)\end{array}$ & $\begin{array}{l}\text { No-varices group } \\
(n=20)\end{array}$ & $\begin{array}{l}\text { Healthy subjects } \\
(n=20)\end{array}$ \\
\hline \multicolumn{5}{|l|}{ Serum sCD163, mg/L } \\
\hline Range & $2.99-13.59$ & $1.70-5.15$ & $1.56-3.60$ & $1.50-2.70$ \\
\hline Median & 4.35 & 3.80 & 3.01 & 2.15 \\
\hline Mean \pm SD & $5.27 \pm 2.407$ & $3.68 \pm 0.824$ & $2.91 \pm 0.661$ & $2.08 \pm 0.343$ \\
\hline $\mathrm{H}, p$ value & \multicolumn{4}{|l|}{$\mathrm{H}=68.019^{*}, p$} \\
\hline Significance between groups & \multicolumn{4}{|c|}{$p_{1}<0.001^{*}, p_{2}<0.001^{*}, p_{3}<0.001^{*}, p_{4}=0.062, p_{5}=0.044^{*}, p_{6}=0.896$} \\
\hline
\end{tabular}

H, Kruskal-Wallis test. Pairwise comparison between each 2 groups was done using the post hoc test (Dunn's test for multiple comparisons). * Statistically significant at $p \leq 0.05$. $p$, $p$ value for comparing between the different studied groups. $p_{1}, p$ value for comparing bleeder group and nonbleeder group; $p_{2}, p$ value for comparing bleeder group and no-varices group; $p_{3}, p$ value for comparing bleeder group and healthy subjects; $p_{4}, p$ value for comparing nonbleeder group and no-varices group; $p_{5}, p$ value for comparing between nonbleeder group and healthy subjects; $p_{6}, p$ value for comparing no-varices group and healthy subjects.

Fig. 1. Statistical comparison between the groups of cirrhotic patients included in the study and healthy subjects as regards soluble CD163 (sCD163) serum levels (mg/L).

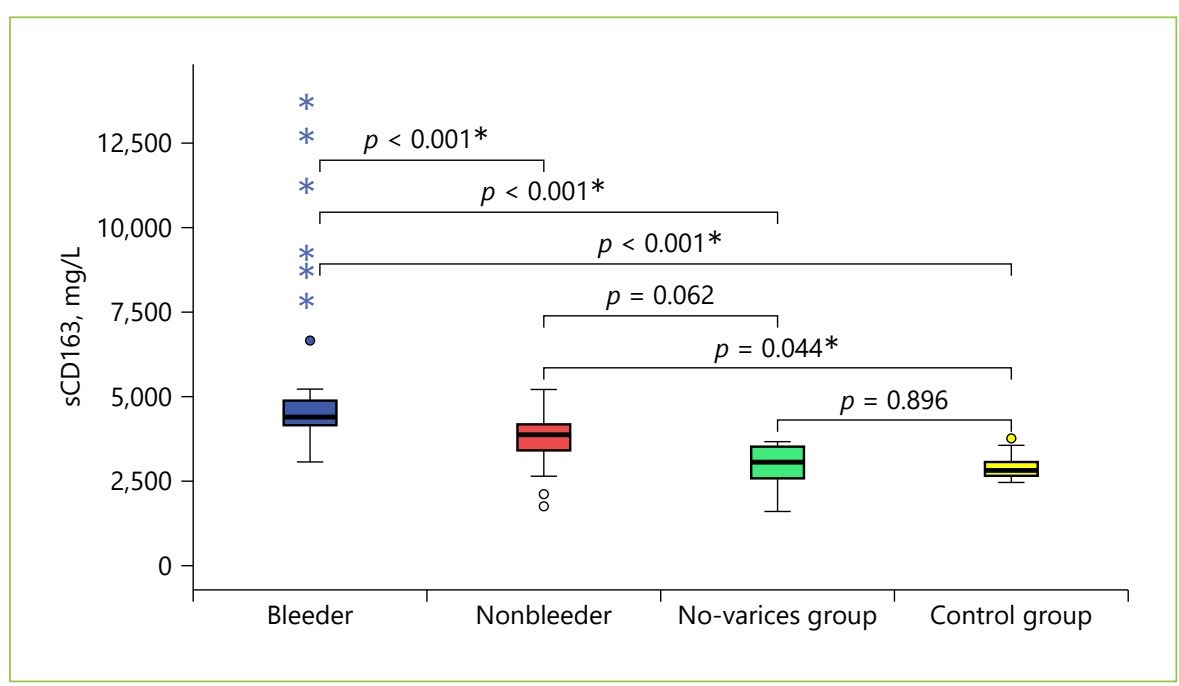

rum $\mathrm{sCD} 163$ levels showed a significant increase in all the groups of cirrhotic patients compared to healthy subjects $(p<0.001)$ with a stepwise increase among the no-varices group, the nonbleeder group, and the bleeder group sequentially (Table 2; Fig. 1).

\section{Statistical Correlation of $s$ CD163 and the Other Calculated Noninvasive Parameters (APRI, FIB-4, \\ PSR) to the Variceal Grade and Risk Signs}

The mean value of serum sCD163 correlated positively with the grade of EV and the presence of variceal risk signs in the total sample of cirrhotic patients $(p<0.001$ each) as well as in cirrhotic patients of both the bleeder group and the nonbleeder group ( $p=0.002, p<0.001$ and $p=0.004, p<0.001$, respectively; Tables 3,4$)$.

The mean value of APRI showed a positive correlation with the grade of EV and the presence of variceal risk signs in the total sample of cirrhotic patients $(p<$ 0.001 each) and in cirrhotic patients of the nonbleeder group ( $p=0.006$ each) but not cirrhotic patients of the bleeder group ( $p=0.103$ and $p=0.079$, respectively; Tables 3,4$)$. Also, the mean value of FIB-4 correlated positively with the grade of $\mathrm{EV}$ and the presence of variceal risk signs in the total sample of cirrhotic patients $(p<$ 0.001 each) and in cirrhotic patients of the nonbleeder group ( $p<0.001$ each) but not cirrhotic patients of the 
Table 3. Statistical correlation of soluble CD163 (sCD163) and the other calculated noninvasive parameters (APRI, FIB-4, PSR) to the variceal grade in the total sample and each group of cirrhotic patients included in the study

\begin{tabular}{cccc}
\hline \multicolumn{3}{c}{ Variceal grade } & \\
\cline { 2 - 4 } & bleeder & nonbleeder & total sample \\
\hline sCD163 & & & \\
$r$ & 0.467 & 0.691 & 0.709 \\
$p$ & $0.002^{*}$ & $<0.001^{*}$ & $<0.001^{*}$ \\
APRI & & & \\
$r$ & 0.261 & 0.424 & 0.434 \\
$p$ & 0.103 & $0.006^{*}$ & $<0.001^{*}$ \\
FIB-4 & 0.296 & 0.702 & 0.568 \\
$r$ & 0.064 & $<0.001^{*}$ & $<0.001^{*}$ \\
$p$ & & & \\
PSR & -0.621 & -0.752 & -0.772 \\
$r$ & $<0.001^{*}$ & $<0.001^{*}$ & $<0.001^{*}$ \\
$p$ & &
\end{tabular}

APRI, aspartate aminotransferase-to-platelet count ratio index; FIB-4, fibrosis-4 index; PSR, platelet count-to-spleen diameter ratio; sCD163, soluble CD163. * Statistically significant at $p \leq$ 0.05 .

bleeder group ( $p=0.064$ and $p=0.153$, respectively; Tables 3,4$)$. However, the mean value of PSR correlated negatively with the grade of EV and the presence of variceal risk signs in the total sample of cirrhotic patients $(p<0.001$ each $)$ as well as in cirrhotic patients of both the bleeder group and the nonbleeder group $(p<0.001$ each; Tables 3, 4).

\section{Performance of sCD163 to Predict EV Presence in Cirrhotic Patients}

Serum sCD163 at the cutoff value of $3.6 \mathrm{mg} / \mathrm{L}$ significantly predicted EV presence in cirrhotic patients with $100 \%$ sensitivity and $100 \%$ NPV (AUC $=0.888$, accuracy $=80 \%, p<0.001)$ (Table 5; Fig. 2).

\section{Performance of $s C D 163$ and the Other Calculated \\ Noninvasive Parameters (APRI, FIB-4, PSR) to \\ Predict High-Grade and High-Risk EV in Cirrhotic \\ Patients}

Serum sCD163 at a cutoff value $>4 \mathrm{mg} / \mathrm{L}$ yielded significant prediction of cirrhotic patients with large-size $\mathrm{EV}(\mathrm{AUC}=0.910$, accuracy $=82 \%, p<0.001$; Table 6; Fig. 3) and high-risk $E V(A U C=0.939$, accuracy $=87.8 \%$, $p<0.001$; Table 7; Fig. 4). Moreover, serum sCD163 at the same cutoff value significantly predicted the risk of index
Table 4. Statistical correlation of soluble CD163 (sCD163) and the other calculated noninvasive parameters (APRI, FIB-4, PSR) to the variceal risk signs in the total sample and each group of cirrhotic patients included in the study

\begin{tabular}{cccc}
\hline \multicolumn{4}{l}{ Variceal risk signs } \\
\cline { 2 - 4 } & bleeder & nonbleeder & total sample \\
\hline sCD163 & & \\
$r$ & 0.447 & 0.789 & 0.752 \\
$p$ & $0.004^{*}$ & $<0.001^{*}$ & $<0.001^{*}$ \\
APRI & & & \\
$r$ & 0.281 & 0.431 & 0.445 \\
$p$ & 0.079 & $0.006^{*}$ & $<0.001^{*}$ \\
FIB-4 & & & \\
$r$ & 0.230 & 0.652 & 0.521 \\
$p$ & 0.153 & $<0.001^{*}$ & $<0.001^{*}$ \\
PSR & & & -0.772 \\
$r$ & -0.567 & -0.743 & $<0.001^{*}$ \\
$p$ & $<0.001^{*}$ & $<0.001^{*}$ & \\
\hline
\end{tabular}

APRI, aspartate aminotransferase-to-platelet count ratio index; FIB-4, fibrosis-4 index; PSR, platelet count-to-spleen diameter ratio; sCD163, soluble CD163. * Statistically significant at $p \leq$ 0.05 .

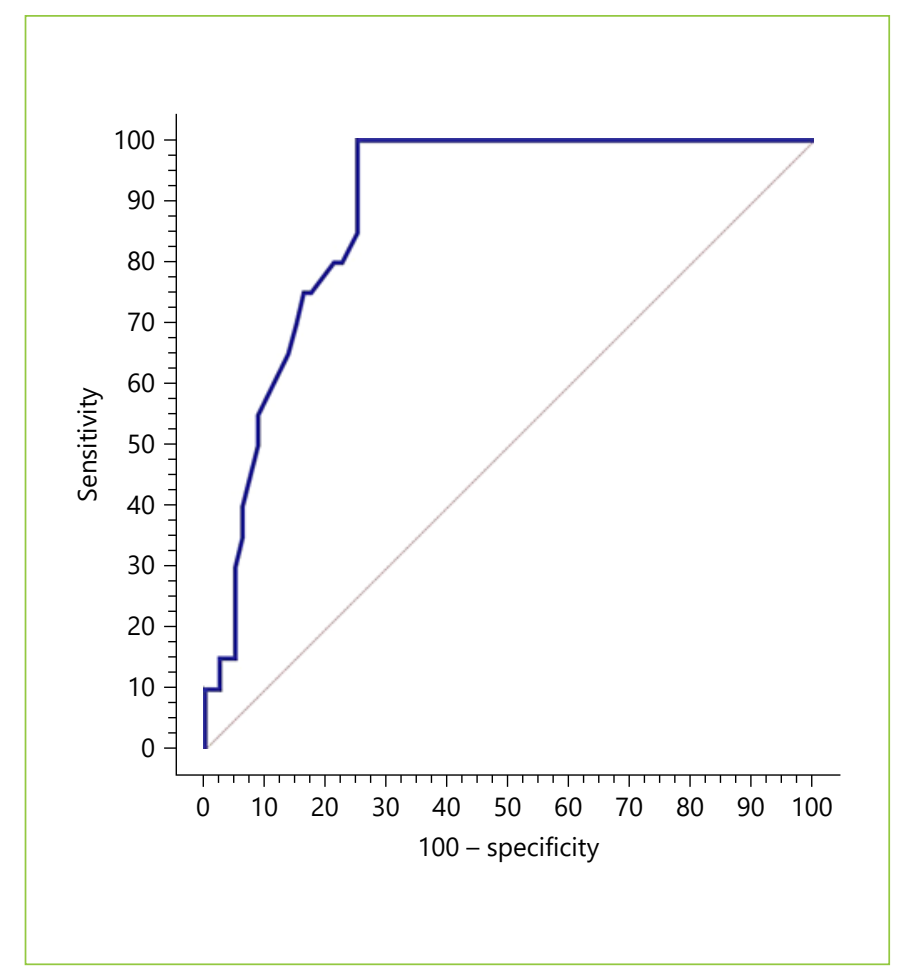

Fig. 2. Performance of soluble CD163 (sCD163) to predict presence of esophageal varices in the total sample of cirrhotic patients included in the study. 
Table 5. Performance of soluble CD163 (sCD163) to predict EV presence in the total sample of cirrhotic patients included in the study

\begin{tabular}{|c|c|c|c|c|c|c|c|c|c|c|}
\hline & \multirow[t]{2}{*}{ AUC } & \multirow[t]{2}{*}{$p$ value } & \multicolumn{2}{|c|}{$95 \% \mathrm{CI}$} & \multirow[t]{2}{*}{ Cutoff } & \multirow[t]{2}{*}{ Sensitivity } & \multirow[t]{2}{*}{ Specificity } & \multirow[t]{2}{*}{ PPV } & \multirow[t]{2}{*}{ NPV } & \multirow[t]{2}{*}{ Accuracy } \\
\hline & & & LL & UL & & & & & & \\
\hline sCD163 & 0.888 & $<0.001^{*}$ & 0.809 & 0.942 & $\leq 3.6$ & 100 & 75.00 & 50.0 & 100 & 80.00 \\
\hline
\end{tabular}

AUC, area under the curve; CI, confidence interval; LL, lower limit; UL, upper limit; PPV, positive predictive value; NPV, negative predictive value; sCD163, soluble CD163. * Statistically significant at $p \leq 0.05$.

Table 6. Performance of soluble CD163 (sCD163) and the other calculated noninvasive parameters (APRI, FIB4 , PSR) to predict high-grade esophageal varices in the total sample of cirrhotic patients included in the study

\begin{tabular}{|c|c|c|c|c|c|c|c|c|c|c|}
\hline & \multirow[t]{2}{*}{ AUC } & \multirow[t]{2}{*}{$p$ value } & \multicolumn{2}{|c|}{$95 \%$ CI } & \multirow[t]{2}{*}{ Cutoff } & \multirow[t]{2}{*}{ Sensitivity } & \multirow[t]{2}{*}{ Specificity } & \multirow[t]{2}{*}{ PPV } & \multirow[t]{2}{*}{ NPV } & \multirow[t]{2}{*}{ Accuracy } \\
\hline & & & LL & UL & & & & & & \\
\hline sCD163 & 0.910 & $<0.001^{*}$ & 0.825 & 0.963 & $>4.0$ & 95.35 & 78.38 & 83.7 & 87.80 & 82.00 \\
\hline APRI & 0.749 & $<0.001^{*}$ & 0.639 & 0.839 & $>1.6$ & 39.53 & 100.00 & 100.0 & 51.40 & 49.80 \\
\hline FIB-4 & 0.829 & $<0.001^{*}$ & 0.728 & 0.904 & $>3.68$ & 83.70 & 73.00 & 78.3 & 60.80 & 65.80 \\
\hline PSR & 0.947 & $<0.001^{*}$ & 0.872 & 0.984 & $\leq 685$ & 83.70 & 91.90 & 92.3 & 87.00 & 89.40 \\
\hline
\end{tabular}

AUC, area under the curve; CI, confidence interval; LL, lower limit; UL, upper limit; PPV, positive predictive value, NPV, negative predictive value; APRI, aspartate aminotransferase-to-platelet count ratio index; FIB-4, fibrosis-4 index; PSR, platelet count-to-spleen diameter ratio; sCD163, soluble CD163. * Statistically significant at $p \leq 0.05$.

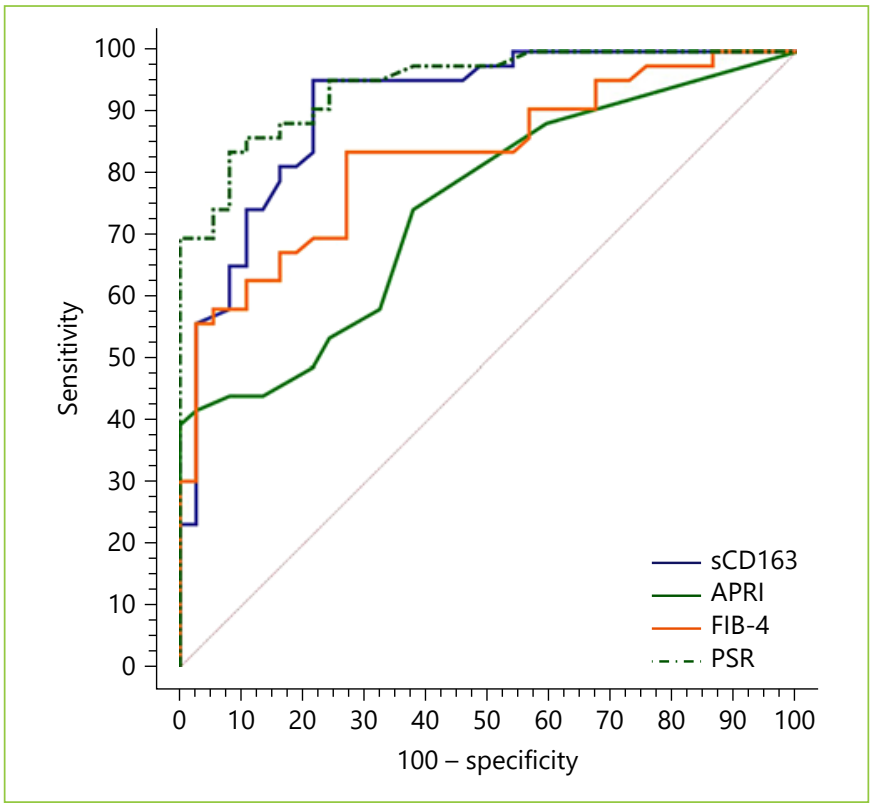

Fig. 3. Performance of soluble CD163 (sCD163) and the other calculated noninvasive parameters (APRI, FIB-4, PSR) to predict high-grade esophageal varices in the total sample of cirrhotic patients included in the study.

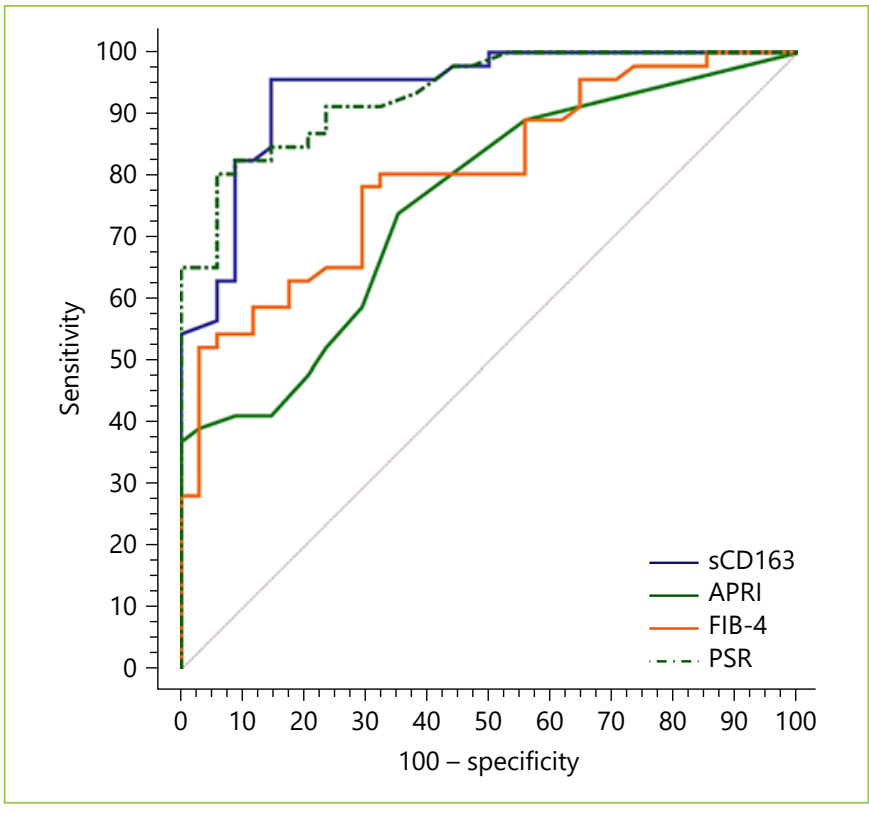

Fig. 4. Performance of soluble CD163 (sCD163) and the other calculated noninvasive parameters (APRI, FIB-4, PSR) to predict high-risk esophageal varices in the total sample of cirrhotic patients included in the study. 
Table 7. Performance of soluble CD163 (sCD163) and the other calculated noninvasive parameters (APRI, FIB4 , PSR) to predict high-risk esophageal varices in the total sample of cirrhotic patients included in the study

\begin{tabular}{|c|c|c|c|c|c|c|c|c|c|c|}
\hline & \multirow[t]{2}{*}{ AUC } & \multirow[t]{2}{*}{$p$ value } & \multicolumn{2}{|c|}{$95 \%$ CI } & \multirow[t]{2}{*}{ Cutoff } & \multirow[t]{2}{*}{ Sensitivity } & \multirow[t]{2}{*}{ Specificity } & \multirow[t]{2}{*}{ PPV } & \multirow[t]{2}{*}{ NPV } & \multirow[t]{2}{*}{ Accuracy } \\
\hline & & & LL & $\mathrm{UL}$ & & & & & & \\
\hline sCD163 & 0.939 & $<0.001^{*}$ & 0.862 & 0.980 & $>4.0$ & 95.70 & 85.30 & 89.8 & 95.40 & 87.80 \\
\hline APRI & 0.757 & $<0.001^{*}$ & 0.648 & 0.846 & $>0.80$ & 73.90 & 64.70 & 73.90 & 50.20 & 51.40 \\
\hline FIB-4 & 0.804 & $<0.001^{*}$ & 0.700 & 0.884 & $>4.83$ & 52.17 & 97.06 & 96.0 & 78.80 & 60.80 \\
\hline PSR & 0.935 & $<0.001^{*}$ & 0.857 & 0.978 & $\leq 685$ & 80.43 & 94.12 & 94.90 & 89.80 & 87.00 \\
\hline
\end{tabular}

AUC, area under the curve; CI, confidence interval; LL, lower limit; UL, upper limit; PPV, positive predictive value; NPV, negative predictive value; APRI, aspartate aminotransferase-to-platelet count ratio index; FIB-4, fibrosis-4 index; PSR, platelet count-to-spleen diameter ratio; sCD163, soluble CD163. * Statistically significant at $p \leq 0.05$.

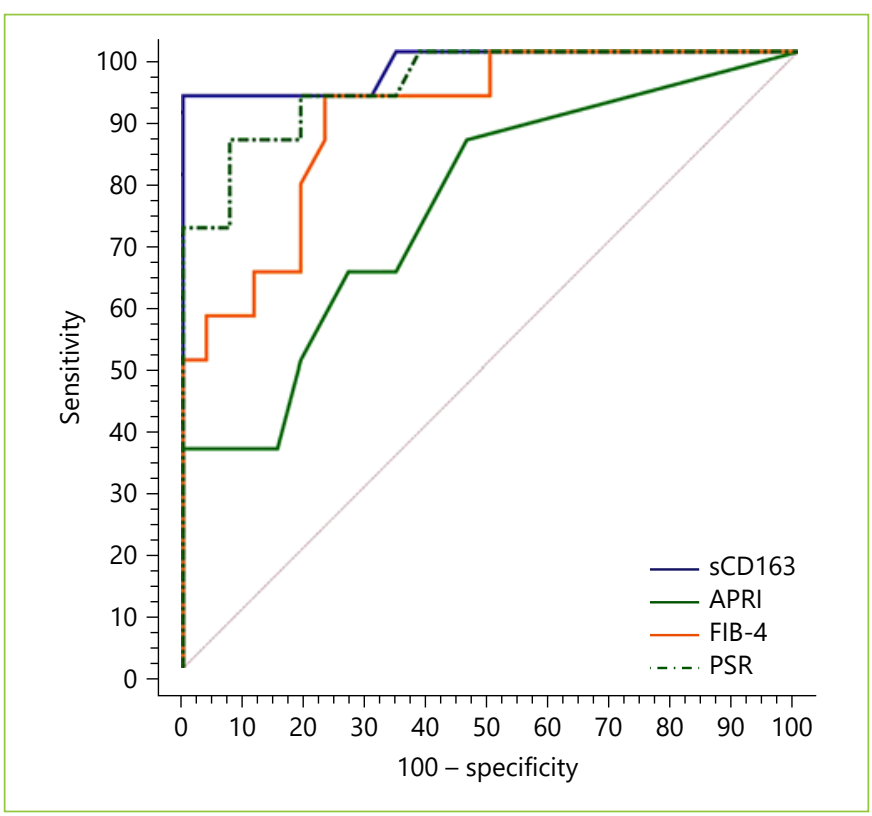

Fig. 5. Performance of soluble CD163 (sCD163) and the other calculated noninvasive parameters (APRI, FIB-4, PSR) to predict the risk of index bleed in cirrhotic patients of the nonbleeder group included in the study.

bleed in the nonbleeder group with 100\% PPV (AUC = 0.977 , accuracy $=95.4 \%, p<0.001$; Table 8; Fig. 5).

All the other calculated noninvasive parameters performed significantly for prediction of high-grade and high-risk EV with considerable sensitivities and specificities. Amongst them, PSR at a cutoff value $\leq 685$ had the best diagnostic performance in identifying cirrhotic patients with large-size EV (AUC $=0.947$, accuracy $=89.4 \%$, $p<0.001$; Table 6; Fig. 3) and cirrhotic patients with highrisk $\mathrm{EV}(\mathrm{AUC}=0.935$, accuracy $=87 \%, p<0.001$; Table

Soluble CD163 and Esophageal Variceal Hemorrhage

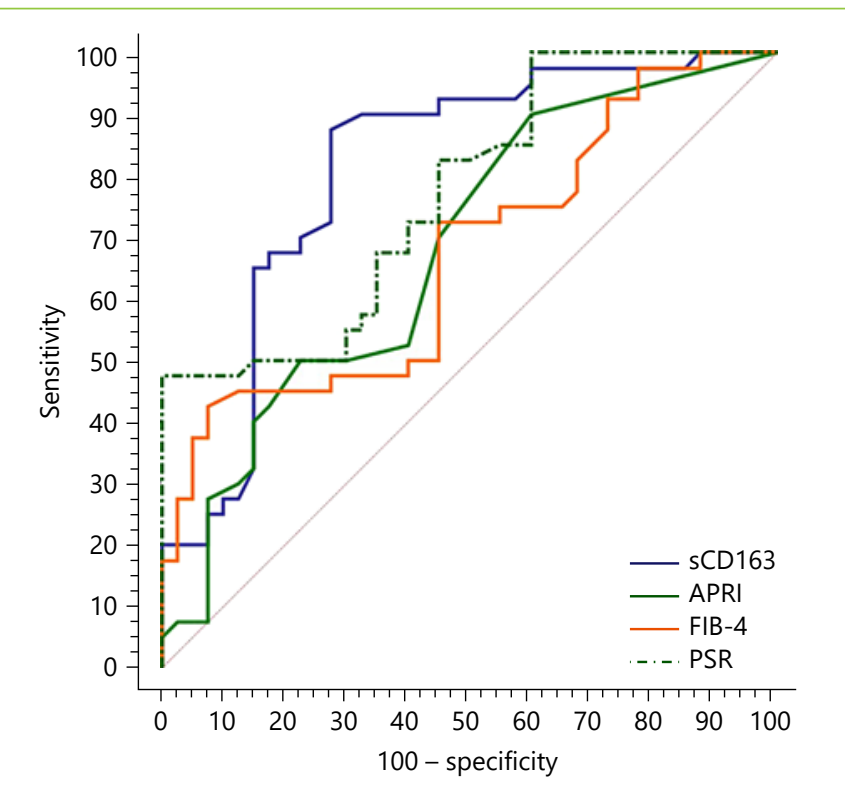

Fig. 6. Performance of soluble CD163 (sCD163) and the other calculated noninvasive parameters (APRI, FIB-4, PSR) to predict variceal hemorrhage occurrence in the total sample of cirrhotic patients included in the study.

7; Fig. 4). Moreover, PSR at a cutoff value $\leq 673.33$ significantly predicted the risk of index-bleed in the nonbleeder group with $85.7 \%$ PPV $(\mathrm{AUC}=0.949$, accuracy = $89.8 \%, p<0.001$; Table 8; Fig. 5).

\section{Performance of sCD163 and the Other Calculated}

Noninvasive Parameters (APRI, FIB-4, PSR) to

Predict VH Occurrence in Cirrhotic Patients

Serum sCD163 at a cutoff value $>4.05 \mathrm{mg} / \mathrm{L}$ (AUC $=$ 0.811 , accuracy $=62.2 \%, p<0.001)$ modestly discrimi- 
Table 8. Performance of soluble CD163 (sCD163) and the other calculated noninvasive parameters (APRI, FIB4 , PSR) to predict the risk of index bleed in cirrhotic patients of the nonbleeder group included in the study

\begin{tabular}{|c|c|c|c|c|c|c|c|c|c|c|}
\hline & \multirow[t]{2}{*}{ AUC } & \multirow[t]{2}{*}{$p$ value } & \multicolumn{2}{|c|}{$95 \%$ CI } & \multirow[t]{2}{*}{ Cutoff } & \multirow[t]{2}{*}{ Sensitivity } & \multirow[t]{2}{*}{ Specificity } & \multirow[t]{2}{*}{ PPV } & \multirow[t]{2}{*}{ NPV } & \multirow[t]{2}{*}{ Accuracy } \\
\hline & & & LL & $\mathrm{UL}$ & & & & & & \\
\hline sCD163 & 0.977 & $<0.001^{*}$ & 0.871 & 1.000 & $>4.0$ & 92.9 & 100 & 100 & 62.20 & 95.40 \\
\hline APRI & 0.751 & $0.002 *$ & 0.590 & 0.874 & $>0.7$ & 85.7 & 53.85 & 50 & 36.00 & 50.20 \\
\hline FIB-4 & 0.894 & $<0.001^{*}$ & 0.756 & 0.969 & $>3.58$ & 92.9 & 76.9 & 68.4 & 34.40 & 78.80 \\
\hline PSR & 0.949 & $<0.001^{*}$ & 0.830 & 0.994 & $\leq 673.33$ & 85.7 & 92.3 & 85.7 & 54.00 & 89.80 \\
\hline
\end{tabular}

AUC, area under the curve; CI, confidence interval; LL, lower limit; UL, upper limit; PPV, positive predictive value; NPV, negative predictive value; APRI, aspartate aminotransferase-to-platelet count ratio index; FIB-4, fibrosis-4 index; PSR, platelet count-to-spleen diameter ratio; sCD163, soluble CD163. * Statistically significant at $p \leq 0.05$.

Table 9. Performance of soluble CD163 (sCD163) and the other calculated noninvasive parameters (APRI, FIB4 , PSR) to predict variceal hemorrhage occurrence in the total sample of cirrhotic patients included in the study

\begin{tabular}{|c|c|c|c|c|c|c|c|c|c|c|}
\hline & \multirow[t]{2}{*}{ AUC } & \multirow{2}{*}{$p$ value } & \multicolumn{2}{|c|}{$95 \%$ CI } & \multirow[t]{2}{*}{ Cutoff } & \multirow[t]{2}{*}{ Sensitivity } & \multirow[t]{2}{*}{ Specificity } & \multirow[t]{2}{*}{ PPV } & \multirow[t]{2}{*}{ NPV } & \multirow[t]{2}{*}{ Accuracy } \\
\hline & & & LL & UL & & & & & & \\
\hline sCD163 & 0.811 & $<0.001^{*}$ & 0.708 & 0.890 & $>4.05$ & 87.5 & 72.5 & 76.1 & 85.3 & 62.20 \\
\hline APRI & 0.680 & $0.003^{*}$ & 0.567 & 0.780 & $>0.7$ & 90.0 & 40.0 & 60.0 & 80.0 & 36.00 \\
\hline FIB-4 & 0.672 & $0.005^{*}$ & 0.558 & 0.773 & $>5.01$ & 42.5 & 92.5 & 85.0 & 61.7 & 34.40 \\
\hline PSR & 0.770 & $<0.001^{*}$ & 0.663 & 0.857 & $\leq 678.95$ & 47.5 & 100.0 & 100.0 & 65.6 & 54.00 \\
\hline
\end{tabular}

AUC, area under the curve; CI, confidence interval; LL, lower limit; UL, upper limit; PPV, positive predictive value; NPV, negative predictive value; APRI, aspartate aminotransferase-to-platelet count ratio index; FIB-4, fibrosis-4 index; PSR, platelet count-to-spleen diameter ratio; sCD163, soluble CD163. * Statistically significant at $p \leq 0.05$.

nated cirrhotic patients with bleeding EV from cirrhotic patients with EV that had never bled yet with $85.3 \%$ NPV (Table 9; Fig. 6).

PSR at a cutoff value $\leq 678.95$ (AUC $=0.770$, accuracy $=54 \%, p<0.001)$ had the best diagnostic performance among the other calculated noninvasive parameters in discriminating cirrhotic patients with bleeding EV from cirrhotic patients with nonbleeding EV with 100\% PPV (Table 9; Fig. 6).

\section{Discussion/Conclusions}

$\mathrm{PH}$ is a key event in the progression of most CLDs and is responsible for the majority of consequences of liver cirrhosis [1]. Kupffer cells and recruited macrophages play important roles in infection, inflammation, cell death, and fibrogenesis seen in cirrhosis and are often linked to the development of $\mathrm{PH}$-related complications [23]. PH increases bacterial translocation and endotoxemia, which induces an inflammatory response in the liver and in the systemic circulation and increases portal venous pressure [24]. This vicious circle seems to be due to the endotoxin load leading to increased release of variable proinflammatory cytokines, activation of tumor necrosis factor-producing macrophages and monocytes, and subsequent coactivation of hepatic stellate cells leading to fibrosis $[25,26]$. This sequence of events suggested that Kupffer cells, the fixed hepatic macrophages constituting the large majority of body macrophages, play an important role as a mediator between inflammation and $\mathrm{PH}$ [26]. CD163 is a macrophage lineage-related hemoglobin-haptoglobin scavenger receptor and a specific marker for macrophage activation [27]. The soluble form of CD163 is shed into the circulation after Toll-like receptor activation, and the serum concentrations of sCD163 
are accordingly elevated during conditions of macrophage activation and proliferation $[11,28]$.

Patients with liver disease, such as hepatitis and cirrhosis, have high sCD163 levels which is probably related to the high number of activated Kupffer cells with strong CD163 expression in these conditions [14, 16]. Patients with acute hepatic failure have very high serum concentrations of sCD163, comparable with those in patients with macrophage activation syndrome, and a cutoff value of $26 \mathrm{mg} / \mathrm{L}$ identifies patients who are at high risk for mortality with a sensitivity and specificity of 62 and $81 \%$, respectively $[16,29]$. The concentration of sCD163 is highly increased in patients with liver cirrhosis, however, with a large variation among individual patients as related to the severity of the disease [30, 31]. Grønbaek et al. [17] reported that the circulating sCD163 concentration was nearly 3 times higher in cirrhotic patients than in controls. Even greater serum sCD163 levels compared to the values in healthy subjects were reported in other studies $[14,30]$. In cirrhosis, serum sCD163 concentration is positively associated with the model for end-stage liver disease score and the Child-Pugh class, although the association with standard liver tests is weak or absent [14, 17, 30-32]. Moreover, cirrhotic patients who progressed from compensated liver disease showed a mean 2.5 times higher serum sCD163 concentration, and hence it could predict disease progression [30]. Interestingly, serum sCD163 was a strong predictor of overall survival in cirrhotic patients independently of the model for end-stage liver disease score, systemic inflammatory response, age, and gender [31]. These associations have important implications for using sCD163 as a prognostic marker in cirrhosis.

Interestingly, the plasma sCD163 concentration was linearly related to the portal venous pressure even after adjustment for cirrhosis status. This strong positive correlation to $\mathrm{PH}$ has been shown in 2 cohorts of cirrhotic patients and further confirmed in independent studies [14, 17, 31]. Grønbaek et al. [17] found that HVPG rose steeply to an asymptote of $22 \mathrm{~mm} \mathrm{Hg}$ with increasing serum sCD163 up to $5 \mathrm{mg} / \mathrm{L}$ but not to higher values with higher sCD163 levels. A serum sCD163 cutoff value $>3.95$ $\mathrm{mg} / \mathrm{L}(\mathrm{AUC}=0.83)$ predicted $\mathrm{HVPG} \geq 10 \mathrm{~mm} \mathrm{Hg}$ with PPV of $99 \%$, yielding $66 \%$ sensitivity and $94 \%$ specificity. The biological explanation for such an association could be a direct involvement of Kupffer cells in the propagation of portal pressure by release of vasoactive substances and by propagation of fibrous tissue formation $[17,26]$. Holland-Fischer et al. [14] found that Kupffer cells were activated in patients with liver cirrhosis in parallel with their $\mathrm{PH}$; however, interestingly, the serum sCD163 concentra-

Soluble CD163 and Esophageal Variceal Hemorrhage tion did not change after mechanical reduction of portal pressure by installation of a transjugular intrahepatic portosystemic stent. These findings suggested that Kupffer cell activation is a constitutive event which may play a pathogenic role for cirrhotic $\mathrm{PH}$, and that sCD163, being a specific marker of activated macrophages, may independently predict HVPG and identify cirrhotic patients with clinically significant $\mathrm{PH}$, but probably unsuitable for monitoring a reduction in portal venous pressure.

A pathological increase in the HVPG above the threshold of $10 \mathrm{~mm} \mathrm{Hg}$ leads to the formation of portocaval shunts such as GEV with an increased risk of serious bleeding [3]. Supporting the relationship between sCD163 and portal pressure, a large Chinese study showed that the circulating sCD163 level was significantly elevated in cirrhotic patients complicated by EV compared to patients without $\mathrm{EV}(p=0.015)$ [33]. A serum sCD163 cutoff value of $7.05 \mathrm{mg} / \mathrm{L}(\mathrm{AUC}=0.811$ ) was good for predicting the presence of EV with $80 \%$ sensitivity and $89 \%$ specificity. Similarly, other studies found that the serum sCD163 level can distinguish cirrhotic patients having EV from those without varices with good sensitivities and specificities $[14,16,17]$. An Egyptian study found that the mean serum sCD163 level in cirrhotic patients with and without EV was increased fairly 3 times more than that of the control group and nearly doubled in patients with EV than patients without varices $(p=0.001)$; hence, it could potentially predict the presence of EV in Child-Pugh class A cirrhotic patients [34]. Another study found that serum sCD163 is a good noninvasive predictor for the presence of $\mathrm{EV}$ and may be used to determine the grade of varices [35]. It showed that the median serum sCD163 concentration was significantly elevated in cirrhotic patients with and without EV compared to healthy subjects $(p=0.009)$ and significantly higher in patients with large-size EV compared to patients with small-size varices $(p<0.001)$. This study suggested a cutoff value $>191.71 \mathrm{ng} / \mathrm{mL}$ (AUC $=0.82)$ of serum $\mathrm{sCD} 163$ concentration to predict the presence of EV with a PPV of $86.1 \%$, yielding $77.5 \%$ sensitivity and $75 \%$ specificity, and a cutoff value $>199.19 \mathrm{ng} /$ $\mathrm{mL}(\mathrm{AUC}=0.863)$ for the detection of large-size EV with a PPV of $89.5 \%$, yielding $85 \%$ sensitivity and $90 \%$ specificity. Although another study reported that serum sCD163 cannot predict the presence of varices, its concentration was found to be significantly higher in patients with largesize $\mathrm{EV}(p=0.012)$ and varices requiring treatment $(p=$ 0.03 ); hence, it could serve as a good determinant of the grade of EV and the need for interventions [32].

In a cohort of cirrhotic patients, it was shown that patients with high serum sCD163 levels at baseline had a 
significantly higher risk of variceal bleeding in comparison to patients with a low concentration during followup, and a serum sCD163 level $>4,100 \mathrm{ng} / \mathrm{L}$ was associated with $\mathrm{VH}$ independently of the variceal stage and red spots identified by gastroscopy [31]. Similarly, another study showed that serum SCD163 levels were significantly higher in patients at high risk of bleeding $(p=0.04)$, and the bleeder patients who experienced VH $(p=0.001)$ [32]. These studies suggested that plasma sCD163 could be a new independent noninvasive predictor for bleeding from EV in patients with liver cirrhosis.

Based on the results of the present work, the stepwise increase in serum sCD163 concentration in cirrhotic patients with varices and those who bled from $\mathrm{EV}$ compared to those who had never experienced UGIB suggests that the level of sCD163 expression could reflect the severity of $\mathrm{PH}$. Also, the direct correlation of the serum sCD163 level to the grade of EV and the presence of variceal risk signs on endoscopy whatever the state of UGIB indicates that the serum sCD163 concentration could identify a subset group of cirrhotic patients who have varices needing treatment and those at risk of index bleed, so it could help decide on the need for doing endoscopy in order to plan for primary prophylaxis of varices in such cirrhotic patients. Hence; serum sCD163 is a potentially reliable simple noninvasive biomarker of $\mathrm{PH}$, and its use could at least help refine the Baveno VI criteria. Unfortunately, the circulating sCD163 level performed modestly in discriminating cirrhotic patients with bleeding EV from those with EV that had never bled yet, and endoscopy would be required to make a definitive diagnosis of $\mathrm{VH}$ occurrence.

Noninvasive models such as APRI and FIB- 4 were useful in predicting severe liver fibrosis or cirrhosis; however, it remains unknown whether these markers could identify patients without high-risk varices among those who do not meet the Baveno VI criteria [36, 37]. APRI was first introduced as a simple noninvasive test for the diagnosis of significant fibrosis and cirrhosis of various etiologies [19]. Subsequently, studies have shown that APRI correlated with HVPG, and an APRI of $\geq 1.09$ had a diagnostic accuracy of $68 \%$ for predicting HVPG $>12$ $\mathrm{mm} \mathrm{Hg}$ and hence could fairly predict the presence of EV $[38,39]$. Sebastiani et al. [40] suggested APRI at a cutoff value of 1.4 for the prediction of EV and a cutoff value of 1.5 for the detection of large EV. Moreover, other studies proposed APRI at almost similar cutoff values for the prediction of EV [41-43]. However, Stefanescu et al. [44] suggested APRI at a cutoff value $>2.201 \quad($ AUC $=0.538)$ for the detection of large EV. An Egyptian study reported that APRI at a cutoff value $>1.26($ AUC $=0.695)$ could predict the presence of EV with PPV of $81.42 \%$, and APRI at a cutoff value $>1.47(\mathrm{AUC}=0.734)$ could predict large EV [45]. Another study suggested a cutoff value of APRI $>0.16$ for the detection of EV and prediction of large EV [46]. Nevertheless, other studies found that the mean APRI was not significantly different between cirrhotic patients with small EV and those with large EV, and hence unable to predict the grade of $\mathrm{EV}$, although it could identify varices $[34,35]$. A retrospective study of a cohort of cirrhotic and noncirrhotic patients with acute UGIB evaluated APRI, among other noninvasive parameters, as predictors of VH [37]. For all patients with UGIB, APRI appeared to accurately predict the presence of varices prior to endoscopy and to be slightly less accurate in predicting a variceal culprit lesion as the cause of bleeding. For cirrhotic patients with UGIB, however, APRI did not distinguish between a variceal culprit and other lesions, and the optimal cutoff value useful for predicting varices as the culprit bleeding lesion could not be identified.

The FIB- 4 score is a test derived from the Apricot database which produced interesting results as a good noninvasive marker of liver fibrosis in HCV-related CLD with performances similar to the Fibrotest [20]. FIB-4 was also tried for the prediction of EV in patients with liver cirrhosis [40, 44]. Sebastiani et al. [40] found that FIB-4 could fairly identify $\mathrm{EV}$ at a cutoff value $\geq 3.5$ ( $\mathrm{AUC}=0.64$ ), while the cutoff value $\geq 4.3$ (AUC $=0.63$ ) was good for the prediction of large EV. Stefanescu et al. [44] used FIB-4 for the diagnosis of $\mathrm{EV}$ at a cutoff value $\geq 3.98$, while the cutoff value $\geq 6.75$ performed well for the prediction of large EV. A much lower FIB- 4 cutoff value at 2.8 was proposed in another study for predicting EV with a PPV of $92.7 \%$, yielding $76 \%$ sensitivity and $80 \%$ specificity [47]. Nevertheless, other studies found that the mean FIB-4 was not discriminative between small and large $\mathrm{EV}$, and hence unable to predict the variceal grade, although a high FIB-4 could potentially predict the presence of varices [34,35]. Morishita et al. [48] included patients with HCV-related cirrhosis in a study to assess the clinical usefulness of acoustic radiation force impulse and other noninvasive parameters in the diagnosis of EV presence and risk. The acoustic radiation force impulse had the best diagnostic performance for predicting EV presence and identifying high-risk varices compared with APRI and FIB-4, although the serum-based parameters performed significantly. FIB-4 at a cutoff value of $6.21(\mathrm{AUC}=0.745)$ and APRI at a cutoff value of 1.5 (AUC $=0.684)$ fairly diagnosed the presence of $\mathrm{EV}$ with acceptable performance. Moreover, FIB-4 at a cutoff value of $7.7($ AUC $=0.741)$ and 
APRI at a cutoff value of $1.62($ AUC $=0.669)$ significantly predicted high-risk EV with good accuracy.

The PSR is an easy-to-calculate index that initially showed an excellent performance for the prediction of EV at a cutoff value of 909 , with NPV of $100 \%$ and PPV of $96 \%$, and was confirmed to be reproducible even in the subgroup of patients with compensated disease [21]. Later, a multicenter study using the 909 ratio showed that the test performed less well than in the original study with PPV of $76.6 \%$ and NPV of $87.0 \%$ [49]. In validation studies, the test was less useful when compared with other noninvasive methods for $\mathrm{EV}$ prediction at different cutoff points [50-52]. Nevertheless, an Egyptian study reported a cutoff value of PSR at 939.7, which is very close to that reported by Giannini et al. [49], for prediction of EV presence in cirrhotic patients at $96.5 \%$ diagnostic accuracy [53]. Agha et al. [54] identified a PSR of 792 as the best cutoff value for the presence of EV in patients with compensated HCV-related cirrhosis and suggested that a greater ratio could be useful to identify patients at low risk of having EV on endoscopic surveillance. A modestly lower cutoff value was reported in other studies yielding good sensitivities and specificities for prediction of EV in cirrhotic patients, but it did not appear to predict the grade of varices $[35,55]$. Excitingly, an Egyptian study used a cut-off value of $1,326.58$ for the PSR to predict EV in HCV-related cirrhosis at $96.34 \%$ sensitivity and $94 \%$ diagnostic accuracy [56]. A meta-analysis of 20 studies calculated a sensitivity and specificity of 92 and $87 \%$ for the PSR, respectively, but there was a significant heterogeneity among the included studies, with some of them showing NPV as low as 43\% [57].

A large cohort of Japanese patients with CLD were enrolled in a study to validate the clinical value of liver stiffness-spleen size-to-platelet ratio risk score and other noninvasive parameters for $\mathrm{EV}$ detection and identification of high-risk varices [58]. The liver stiffness-spleen size-toplatelet ratio risk score had the highest discrimination for EV presence and severity, although the other noninvasive parameters performed well. PSR at a cutoff value of 1,330 $(\mathrm{AUC}=0.807)$ and FIB-4 at a cutoff value of $4.1(\mathrm{AUC}=$ $0.779)$ and APRI at a cutoff value of $1.2(\mathrm{AUC}=0.749)$ significantly predicted the presence of EV at high diagnostic accuracies. Moreover, PSR at a cutoff value of 990 $(\mathrm{AUC}=0.817)$ and APRI at a cutoff value of $1.7(\mathrm{AUC}=$ $0.762)$ and FIB- 4 at a cutoff value of $5(\mathrm{AUC}=0.716)$ fairly diagnosed high-risk EV with good performance.

In a cross-sectional study of Indian patients with alcoholic cirrhosis, Kothari et al. [59] found that only the PSR at a cutoff value $<997$ (AUC $=0.656$ ) was significant for

Soluble CD163 and Esophageal Variceal

Hemorrhage predicting EV with a diagnostic accuracy of $52.97 \%$. Interestingly, PSR at a cutoff value $<985($ AUC $=0.78)$ showed a good sensitivity of $81.97 \%$ with a diagnostic accuracy of $68.81 \%$ for the prediction of $\mathrm{VH}$ on follow-up. Also, FIB-4 at a cut-off value $>3.91$ (AUC $=0.74$ ) performed well for the diagnosis of $\mathrm{VH}$, yielding sensitivity of $72.13 \%$ and specificity of $60.28 \%$ with a diagnostic accuracy of $63.86 \%$. Meanwhile, APRI at a cutoff value $>1.05($ AUC $=0.72)$ showed lower sensitivity and specificity for the prediction of $\mathrm{VH}$. This study suggested that PSR and FIB-4 may be the most useful among the armamentarium of noninvasive parameters for predicting the risk of VH in alcoholic cirrhosis. Nevertheless, in another study, Kraja et al. [60] found that none of the noninvasive parameters turned out to be a useful predictor of the index VH during the follow-up of nonbleeder patients with liver cirrhosis of variable etiologies.

Based on the results of the present work, the association of APRI, FIB-4, and PSR parameters to the grade of $\mathrm{EV}$ and the presence of variceal risk signs on endoscopy indicates that these noninvasive parameters could help identify cirrhotic patients with $\mathrm{EV}$ at a high probability of bleeding. Among the calculated noninvasive parameters, PSR yielded the highest discrimination for EV presence and severity, with acceptable predictability of $\mathrm{VH}$ in patients with liver cirrhosis.

In conclusion, the clinical usefulness of serum sCD163 solely or as a supplement to a panel of noninvasive approach to predict clinically significant $\mathrm{PH}$ and its major sequel of $\mathrm{VH}$ in cirrhotic patients could have an important future clinical implication with the objective to substitute for endoscopic surveillance and improve the guidelines for the prophylaxis of EV and management of VH.

In order to correct for the limitations in the present work, it may be recommended that the validity of serum sCD163 to predict the bleeding risk of EV, the occurrence of $\mathrm{VH}$, and even the variceal recurrence after endoscopic obliteration in cirrhotic patients should be extensively studied in prospective longitudinal studies of large-scale populations with inclusion of patients with etiologies of chronic liver disease other than HCV infection. Moreover, future research is imperative to fully explore the potential role of sCD163 in other clinical stages of CLD (like decompensated liver disease) and discover its potential contribution to liver disease progression and prognosis. Further studies to search for any significant role of sCD163 in the pathophysiology of other consequences of $\mathrm{PH}$ (like ascites and spontaneous bacterial peritonitis) should be done as well.

GE Port J Gastroenterol 2022;29:82-95 DOI: $10.1159 / 000516913$ 


\section{Acknowledgment}

The authors would like to deeply thank Prof. Fathallah Ismael for his great help and support in the field of endoscopic management of GEV and VH.

\section{Statement of Ethics}

The research was conducted ethically in accordance with the World Medical Association Declaration of Helsinki. The study protocol was approved by the Institutional Review Board. Informed consent was obtained from all subjects included in the study.

\section{Conflict of Interest Statement}

The authors have no conflict of interest to declare.

\section{Funding Source}

The research did not receive any specific grant from funding agencies in the public, commercial, or not-for-profit sectors.

\section{Author Contributions}

M.Y.T.: concept and design of the work; acquisition of endoscopic data; drafting and revising the work and final approval of the submitted version. A.E.-H.: acquisition of laboratory data; drafting and revising the work and final approval of the submitted version. A.E.-S.: analysis and interpretation of data for the work; drafting and revising the work and final approval of the submitted version. A.S.: collection of data for the work; drafting and revising the work and final approval of the submitted version.

\section{References}

1 D’Amico G, Garcia-Tsao G, Pagliaro L. Natural history and prognostic indicators of survival in cirrhosis: a systematic review of 118 studies. J Hepatol. 2006 Jan;44(1):217-31.

2 de Franchis R; Baveno V Faculty. Revising consensus in portal hypertension: report of the Baveno V consensus workshop on methodology of diagnosis and therapy in portal hypertension. J Hepatol. 2010 Oct;53(4):762-8.

3 Garcia-Tsao G, Sanyal AJ, Grace ND, Carey W; Practice Guidelines Committee of the American Association for the Study of Liver Diseases; Practice Parameters Committee of the American College of Gastroenterology. Prevention and management of gastroesophageal varices and variceal hemorrhage in cirrhosis. Hepatology. 2007 Sep;46(3):922-38.

4 Garcia-Tsao G, Abraldes JG, Berzigotti A, Bosch J. Portal hypertensive bleeding in cirrhosis: Risk stratification, diagnosis, and management: 2016 practice guidance by the American Association for the study of liver diseases. Hepatology. 2017 Jan;65(1):310-35.

5 Bosch J, García-Pagán JC. Prevention of variceal rebleeding. Lancet. 2003 Mar;361(9361): 952-4.

6 Abraldes JG, Villanueva C, Bañares R, Aracil C, Catalina MV, Garci A-Pagán JC, et al.; Spanish Cooperative Group for Portal Hypertension and Variceal Bleeding. Hepatic venous pressure gradient and prognosis in patients with acute variceal bleeding treated with pharmacologic and endoscopic therapy. J Hepatol. 2008 Feb;48(2):229-36.

7 Sharma SK, Aggarwal R. Prediction of large esophageal varices in patients with cirrhosis of the liver using clinical, laboratory and imaging parameters. J Gastroenterol Hepatol. 2007 Nov;22(11):1909-15.

8 de Franchis R; Baveno VI Faculty. Expanding consensus in portal hypertension: Report of the
Baveno VI Consensus Workshop: stratifying risk and individualizing care for portal hypertension. J Hepatol. 2015 Sep;63(3):743-52.

9 Jangouk P, Turco L, De Oliveira A, Schepis F, Villa E, Garcia-Tsao G. Validating, deconstructing and refining Baveno criteria for ruling out high-risk varices in patients with compensated cirrhosis. Liver Int. 2017 Aug;37(8):117783.

10 Augustin S, Pons M, Maurice JB, Bureau C, Stefanescu H, Ney M, et al. Expanding the Baveno VI criteria for the screening of varices in patients with compensated advanced chronic liver disease. Hepatology. 2017 Dec;66(6):1980-8.

11 Schaer DJ, Schleiffenbaum B, Kurrer M, Imhof A, Bächli E, Fehr J, et al. Soluble hemoglobinhaptoglobin scavenger receptor CD163 as a lineage-specific marker in the reactive hemophagocytic syndrome. Eur J Haematol. 2005 Jan;74(1):6-10.

12 Møller HJ. Soluble CD163. Scand J Clin Lab Invest. $2012 \mathrm{Feb} ; 72(1): 1-13$.

13 Etzerodt A, Moestrup SK. CD163 and inflammation: biological, diagnostic, and therapeutic aspects. Antioxid Redox Signal. 2013 Jun; 18(17):2352-63.

14 Holland-Fischer P, Grønbæk H, Sandahl TD, Moestrup SK, Riggio O, Ridola L, et al. Kupffer cells are activated in cirrhotic portal hypertension and not normalised by TIPS. Gut. 2011 Oct;60(10):1389-93.

15 Hiraoka A, Horiike N, Akbar SM, Michitaka K, Matsuyama T, Onji M. Expression of CD163 in the liver of patients with viral hepatitis. Pathol Res Pract. 2005;201(5):379-84.

16 Møller HJ, Grønbaek H, Schiødt FV, HollandFischer P, Schilsky M, Munoz S, et al.; U.S. Acute Liver Failure Study Group. Soluble CD163 from activated macrophages predicts mortality in acute liver failure. J Hepatol. 2007 Nov;47(5):671-6.
17 Grønbaek H, Sandahl TD, Mortensen C, Vilstrup H, Møller HJ, Møller S. Soluble CD163, a marker of Kupffer cell activation, is related to portal hypertension in patients with liver cirrhosis. Aliment Pharmacol Ther. 2012 Jul; 36(2):173-80.

18 Buck M, Garcia-Tsao G, Groszmann RJ, Stalling C, Grace ND, Burroughs AK, et al. Novel inflammatory biomarkers of portal pressure in compensated cirrhosis patients. Hepatology. 2014 Mar;59(3):1052-9.

19 Wai CT, Greenson JK, Fontana RJ, Kalbfleisch JD, Marrero JA, Conjeevaram HS, et al. A simple noninvasive index can predict both significant fibrosis and cirrhosis in patients with chronic hepatitis C. Hepatology. 2003 Aug; 38(2):518-26.

20 Sterling RK, Lissen E, Clumeck N, Sola R, Correa MC, Montaner J, et al.; APRICOT Clinical Investigators. Development of a simple noninvasive index to predict significant fibrosis in patients with HIV/HCV coinfection. Hepatology. 2006 Jun;43(6):1317-25.

21 Giannini E, Botta F, Borro P, Risso D, Romagnoli P, Fasoli A, et al. Platelet count/spleen diameter ratio: proposal and validation of a noninvasive parameter to predict the presence of oesophageal varices in patients with liver cirrhosis. Gut. 2003 Aug;52(8):1200-5.

22 Walker JM, editor. The protein protocols handbook. 3rd ed. New York: Humana Press; 2009. p. 1827-33.

23 Tacke F, Zimmermann HW. Macrophage heterogeneity in liver injury and fibrosis. J Hepatol. 2014 May;60(5):1090-6.

24 Ruiz-del-Arbol L, Urman J, Fernández J, González M, Navasa M, Monescillo A, et al. Systemic, renal, and hepatic hemodynamic derangement in cirrhotic patients with spontaneous bacterial peritonitis. Hepatology. 2003 Nov;38(5):1210-8. 
25 Pérez del Pulgar S, Pizcueta P, Engel P, Bosch J. Enhanced monocyte activation and hepatotoxicity in response to endotoxin in portal hypertension. J Hepatol. 2000 Jan;32(1):25-31.

26 Steib CJ, Gerbes AL, Bystron M, Op den Winkel M, Härtl J, Roggel F, et al. Kupffer cell activation in normal and fibrotic livers increases portal pressure via thromboxane A(2). J Hepatol. 2007 Aug;47(2):228-38.

27 Moestrup SK, Møller HJ. CD163: a regulated hemoglobin scavenger receptor with a role in the anti-inflammatory response. Ann Med. 2004;36(5):347-54.

28 Weaver LK, Hintz-Goldstein KA, Pioli PA, Wardwell K, Qureshi N, Vogel SN, et al. Pivotal advance: activation of cell surface Toll-like receptors causes shedding of the hemoglobin scavenger receptor CD163. J Leukoc Biol. 2006 Jul;80(1):26-35.

29 Hiraoka A, Horiike N, Akbar SM, Michitaka K, Matsuyama T, Onji M. Soluble CD163 in patients with liver diseases: very high levels of soluble CD163 in patients with fulminant hepatic failure. J Gastroenterol. 2005 Jan;40(1):52-6.

30 Rode A, Nicoll A, Møller HJ, Lim L, Angus PW, Kronborg I, et al. Hepatic macrophage activation predicts clinical decompensation in chronic liver disease. Gut. 2013 Aug;62(8):1231-2.

31 Waidmann O, Brunner F, Herrmann E, Zeuzem S, Piiper A, Kronenberger B. Macrophage activation is a prognostic parameter for variceal bleeding and overall survival in patients with liver cirrhosis. J Hepatol. 2013 May;58(5): 956-61.

32 Fouad R, Hamza I, Khairy M, Elsharkawy M, Helmy AA. Role of serum soluble CD163 in the diagnosis, risk of bleeding and prognosis of gastro-esophageal varices in cirrhotic patients. J Interferon Cytokine Res. 2017 Mar;37(3):112-

33 Yang YY, Hou MC, Lin MW, Chen PH, Liao WC, Chu CJ, et al. Combined platelet count with $\mathrm{sCD} 163$ and genetic variants optimizes esophageal varices prediction in cirrhotic patients. J Gastroenterol Hepatol. 2013 Jan;28(1): $112-21$.

34 Mostafa AA, El-Shewi ME, Amin AM, Alibiary SH. Assessment of CD163 as a predictor of esophageal varices in patients with liver cirrhosis. NY Sci J. 2016;9(10):37-47.

35 Abdo AE, El Din KM, Bedewy EE, Abo Elwafa RA, Abdel Aziz MA. Plasma soluble CD 163 level as a marker of oesophageal varices in cirrhotic patients. Alex J Med. 2018;54(4):567-80.

36 Lok AS, Ghany MG, Goodman ZD, Wright EC, Everson GT, Sterling RK, et al. Predicting cirrhosis in patients with hepatitis $\mathrm{C}$ based on standard laboratory tests: results of the HALTC cohort. Hepatology. 2005 Aug;42(2):282-92.

37 Rockey DC, Elliott A, Lyles T. Prediction of esophageal varices and variceal hemorrhage in patients with acute upper gastrointestinal bleeding. J Investig Med. 2016 Mar;64(3):74551.

Soluble CD163 and Esophageal Variceal Hemorrhage
38 Forestier J, Dumortier J, Guillaud O, Ecochard $\mathrm{M}$, Roman S, Boillot $\mathrm{O}$, et al. Noninvasive diagnosis and prognosis of liver cirrhosis: a comparison of biological scores, elastometry, and metabolic liver function tests. Eur J Gastroenterol Hepatol. 2010 May;22(5):532-40.

39 Mattos AZ, Alves de Mattos A, Daros LF, Musskopf MI. Aspartate aminotransferase-toplatelet ratio index (APRI) for the non-invasive prediction of esophageal varices. Ann Hepatol. 2013 Sep-Oct; 12(5):810-4.

40 Sebastiani G, Tempesta D, Fattovich G, Castera L, Halfon P, Bourliere M, et al. Prediction of oesophageal varices in hepatic cirrhosis by simple serum non-invasive markers: results of a multicenter, large-scale study. J Hepatol. 2010 Oct:53(4):630-8.

41 Castéra L, Le Bail B, Roudot-Thoraval F, Bernard PH, Foucher J, Merrouche W, et al. Early detection in routine clinical practice of cirrhosis and oesophageal varices in chronic hepatitis C: comparison of transient elastography (FibroScan) with standard laboratory tests and non-invasive scores. J Hepatol. 2009 Jan;50(1): 59-68.

42 Tafarel JR, Tolentino LH, Correa LM, Bonilha DR, Piauilino P, Martins FP, et al. Prediction of esophageal varices in hepatic cirrhosis by noninvasive markers. Eur J Gastroenterol Hepatol. 2011 Sep;23(9):754-8.

43 Adami MR, Ferreira CT, Kieling CO, Hirakata V, Vieira SM. Noninvasive methods for prediction of esophageal varices in pediatric patients with portal hypertension. World J Gastroenterol. 2013 Apr;19(13):2053-9.

44 Stefanescu H, Grigorescu M, Lupsor M, Maniu A, Crisan D, Procopet B, et al. A new and simple algorithm for the noninvasive assessment of esophageal varices in cirrhotic patients using serum fibrosis markers and transient elastography. J Gastrointestin Liver Dis. 2011 Mar; 20(1):57-64.

45 Shehata M. AboAli LA, El-Shafey K, El-Hossary M. A comparative study of Duplex Doppler ultrasound and blood indices as noninvasive predictors of oesophageal varices in cirrhotic patients. Tanta Med J. 2014;42(3):83-91.

46 Galal GM, Ghweil AA, Muhammad EM, Yousef LM. Clinical utility of simple fibrosis markers in prediction of oesophageal varices in chronic hepatitis $\mathrm{C}$ patients with advanced fibrosis. Med J Cairo Univ. 2012;80:85-93.

47 Hassan EM, Omran DA, El Beshlawey ML, Abdo M, El Askary A. Can transient elastography, Fib-4, Forns Index, and Lok Score predict esophageal varices in HCV-related cirrhotic patients? Gastroenterol Hepatol. 2014 Feb; 37(2):58-65.

48 Morishita N, Hiramatsu N, Oze T, Harada N, Yamada R, Miyazaki M, et al. Liver stiffness measurement by acoustic radiation force impulse is useful in predicting the presence of esophageal varices or high-risk esophageal varices among patients with HCV-related cirrhosis. J Gastroenterol. 2014 Jul;49(7):1175-82.
49 Giannini EG, Zaman A, Kreil A, Floreani A, Dulbecco P, Testa E, et al. Platelet count/spleen diameter ratio for the noninvasive diagnosis of esophageal varices: results of a multicenter, prospective, validation study. Am J Gastroenterol. 2006 Nov;101(11):2511-9.

50 Abraldes JG, Bureau C, Stefanescu H, Augustin $\mathrm{S}$, Ney M, Blasco H, et al.; Anticipate Investigators. Noninvasive tools and risk of clinically significant portal hypertension and varices in compensated cirrhosis: the "Anticipate" study. Hepatology. 2016 Dec;64(6):2173-84.

51 Berzigotti A, Seijo S, Arena U, Abraldes JG, Vizzutti F, García-Pagán JC, et al. Elastography, spleen size, and platelet count identify portal hypertension in patients with compensated cirrhosis. Gastroenterology. 2013 Jan;144(1):10211.e1.

52 de Mattos AZ, de Mattos AA. Platelet count/ spleen diameter ratio: is there sufficient evidence for its use? Dig Dis Sci. 2012 Sep;57(9): 2473-4.

53 Abu El Makarem MA, Shatat ME, Shaker Y, Abdel Aleem AA, El Sherif AM, Moaty MA, et al. Platelet count/bipolar spleen diameter ratio for the prediction of esophageal varices: The special Egyptian situation: noninvasive prediction of esophageal varices. Hepat Mon. 2011 Apr;11(4):278-84.

54 Agha A, Anwar E, Bashir K, Savarino V, Giannini EG. External validation of the platelet count/spleen diameter ratio for the diagnosis of esophageal varices in hepatitis $C$ virus-related cirrhosis. Dig Dis Sci. 2009 Mar;54(3):654-60.

55 Chandail VS, Kotwal SK, Koul S, Gupta R, Mahajan A. Non-invasive markers for prediction of varices in patients with portal hypertension. Int J Res Med Sci. 2017;5(3):1007-10.

56 Esmat S, Omarn D, Rashid L. Can we consider the right hepatic lobe size/albumin ratio a noninvasive predictor of oesophageal varices in hepatitis $\mathrm{C}$ virus-related liver cirrhotic Egyptian patients? Eur J Intern Med. 2012 Apr;23(3): 267-72.

57 Ying L, Lin X, Xie ZL, Hu YP, Shi KQ. Performance of platelet count/spleen diameter ratio for diagnosis of esophageal varices in cirrhosis: a meta-analysis. Dig Dis Sci. 2012 Jun;57(6): 1672-81.

58 Shibata S, Joshita S, Umemura T, Yamazaki T, Fujimori N, Ichikawa Y, et al. Liver stiffnessspleen size-to-platelet ratio risk score detects esophageal varices in chronic liver disease. Springerplus. 2016 Jul;5(1):998.

59 Kothari HG, Gupta SJ, Gaikwad NR, Sankalecha TH, Samarth AR. Role of non-invasive markers in prediction of esophageal varices and variceal bleeding in patients of alcoholic liver cirrhosis from central India. Turk J Gastroenterol. 2019 Dec;30(12):1036-43.

60 Kraja B, Mone I, Akshija I, Koçollari A, Prifti S, Burazeri G. Predictors of esophageal varices and first variceal bleeding in liver cirrhosis patients. World J Gastroenterol. 2017 Jul;23(26): 4806-14. 